\title{
11
}

\section{The tyranny of neoliberal public management and the challenge for Aboriginal community organisations}

\section{Patrick Sullivan}

\section{Introduction}

When we consider the relationship between indigenous peoples and the state, we tend to narrow down to the policies of the government of the day, as several of the chapters in this volume do. In these studies, the government stands as proxy for the state, even though we are aware that the state is much more pervasive than this. At its most abstract, it is an assemblage of coercive practices tending always to reinforce existing relations of power founded in control of the economy. These practices are instituted by the state's various organs - the judiciary, the police and defence forces, education and the parliament as a whole. None of them are without internal diversity and external rivalries, but they tend to reinforce each other nevertheless. Traditionally, liberal states have balanced what Strakosch calls 'social liberalism' (Strakosch 2015: 21), individual rights and responsibilities, with varying degrees of 'market liberalism', allowing the individuals and corporations that control commercial and industrial production to regulate their own markets. The innovation of neoliberalism is to extend market relations into the social sphere, first by imposing markets on civil society and then by regulating families and 
individuals as if life itself is a commercial activity, albeit one in which the majority of citizens have little or no market power. As Strakosch convincingly argues, the innovation of neoliberalism is that many citizens enter this pseudo-market as social debtors. While traditional liberal states guaranteed citizens entitlements, in neoliberal societies it is the state that is entitled, and liberal rights are extended or withdrawn according to the state's estimate of citizens' capacity to meet their obligations:

the state itself has become morally authoritative and entitled. It makes demands of citizens-that they pay their dues, minimise their risk to society and mitigate their burden on the state through self-reliance. In this task, the neoliberal state joins them as partner and supervisor; it offers assistance through capacity building, but always with the threat of coercion if this capacity is not forthcoming (Strakosch 2015: 25).

Strakosch has analysed the ideology of regulating risk that normalises this intrusion of the state beyond the comfort zone of traditional liberals (Strakosch 2012).

Increasingly, each instance of the neoliberal state subscribes to the same technology of administration, first elaborated as 'new public management' (see Eckersley 2003, O'Flynn 2007), but now frequently simply described as neoliberal public management. This intensification of techniques of control beyond traditional bureaucratic practice into every facet of social life particularly impacts upon previously relatively autonomous, and largely self-governing, organisations such as Indigenous corporations, in ways that the chapters in this volume describe (e.g. Howard-Wagner, Humpage, Page, Bielefeld, McCormack). While case studies of the effects of neoliberal public management are important, equally important is the task of critically analysing contemporary public management as a coercive extension of the state, and considering alternatives. This chapter aims to do so broadly while tying this analysis to the position of Indigenous civil organisations in the Australian polity as a whole.

\section{Neoliberal public management}

In Australia, new public management (NPM), or neoliberal management theory, informed sweeping changes to the Australian Public Service from the mid-1980s to the mid-1990s (Eckersley 2003: 489-92, Nelson 2008: 76-105, Parliament of Australia 2010a). O’Flynn (2007, citing Kaboolian 1998) summarises the core principles of NPM as: 
- Economic markets should be the model for relationships in the public sector

- Policy, implementation and delivery functions should be separated and constructed as a series of contracts

- A range of new administrative technologies should be introduced including performance-based contracting, competition, market incentives and deregulation (O'Flynn 2007: 357).

NPM was a bundle of reforms that intersected with a related trend in politics and public finance-neoliberalism, or market economics. It is common to call NPM 'neoliberal public management', and it is true that it shares many of neoliberalism's values and assumptions. The fundamental assumption is that markets are the fairest and most efficient way of distributing a society's resources. Fake markets are created within the bureaucracy, and by the bureaucracy for its dependent organisations, in order to introduce the magic of capitalism to its fundamentally different order of social activity. As Stoker (2006), summarising Moore's critique, puts it, private enterprise produces private value, public enterprise should produce public value. These are two fundamentally different results requiring fundamentally different processes of production. Contemporary bureaucrats and governments, however, profess to believe in the magical transfer of capitalist properties to public management activities because neoliberal public management delivers another benefit in the guise of efficiency - it tightens social control. Modern public sector management has rediscovered the original project of modern bureaucracy developed in the Anglosphere in the 1850s at the height of unfettered industrial capitalism and colonial expansion. Its present manifestation in strict performance measurement of identified contracted outputs, prospective risk management, itemised accountability for time and resources, and politically 'value neutral' research products and news sources sets a new benchmark in the struggle of high modernism against the human spirit.

Power (1997) has called this the 'audit society'. Citizens are increasingly required to itemise their lives, ascribe each item a value and account for themselves to an impersonal higher authority. The political nature of this accounting has not escaped criticism. Dean Neu, for example, identified the imposition of financial systems on developing countries as 'the software of colonialism' (Neu 2003). It is significant that bureaucracy as a technology of control was scientifically developed in the mid-19th century, the high point of European colonial control and unbridled industrial capitalism. 
They are both expressions of the birth of modernity. Extending Neu's metaphor, accountability is one of the softwares of modernity, of which the hardware is the modern state, and the firmware, or operating system, the contemporary form of bureaucracy. ${ }^{1}$ This has invaded every facet of life. Not only the workspace of commercial organisations and government departments, but increasingly non-government organisations (NGOs) and not-for-profits, and ever outwards embracing aspects of our personal and family lives. So, while this chapter is titled 'the tyranny of neoliberal public management', it is more broadly about 'the diffuse dictatorship of modernity'. It is not the dictatorship of a single despot, but of a managerial class as a whole enforcing, through its senior executives in the political sphere, the unseen requirements of global capital, parsed for the masses as 'economic necessity'.

1 I have been asked, not for the first time, to provide a foundation for the 'normative' tone of this chapter by reference to my previous supportive work. The ideas presented in this chapter have a long tail. In 1989, I submitted a $\mathrm{PhD}$ thesis examining the work of Aboriginal community-controlled organisations in the Kimberley (Sullivan 1991). Part of this, including a chapter on Aboriginal Affairs bureaucracy called 'Rational procedures and irrational results in Aboriginal administration', was subsequently published by the Australian Institute of Aboriginal and Torres Strait Islander Studies (AIATSIS) (Sullivan 1996). Neu's insight, and my critique of new public management, were first advanced at a seminar for the Centre for Aboriginal Economic Policy Research (CAEPR) in 2006, in a paper called 'Softwares of colonialism' (Sullivan 2006a). Refined and developed further, this paper, now called 'Softwares of modernity', was presented to a symposium on Ethnographic Research in the Social and Management Sciences at the School of Management, University of Liverpool (UK) in September 2006 (Sullivan 2006b). This paper was expanded and split to provide contributions to two international journals; one explored the theme of accountability, the other the culture of bureaucracy (Sullivan 2008, 2009) (one received the Outstanding Paper award for its year of publication from the journal editors and the other was in a collection deemed best collection of its year by the publishers). Penetration in Australia has been less marked. I wrote on the importance of the Aboriginal community sector, and the impact of new public management, in a published Working Paper for the Desert Knowledge Cooperative Research Centre in 2010 (Sullivan 2010), a paper that, re-worked, became a chapter in my 2011 book Belonging together (Sullivan 2011a). This book, tracing the changes in Aboriginal policy since the end of the Aboriginal and Torres Strait Islander Commission (ATSIC), perhaps gives the most extended empirical discussion of recent policy supporting the propositions advanced in this chapter. Subsequently, I explored the trajectory of managerialism and normalisation in public policy, introducing Moore's theory of public value, in an article for the Asia Pacific Journal of Anthropology, 'Disenchantment, normalisation and public value' (Sullivan 2013). I also examined alternative approaches to neoliberal public management, including public value, exploring the development of public administration as a field, and its impact on community sector organisations, in an extended essay for the Lowitja Institute in 2015 (Sullivan 2015). 


\section{The logic of neoliberal management and its effect on Aboriginal organisations}

Highly technical 'scientific' public management is necessarily antagonistic to diversity. Correct management procedure stands above local and sectoral differences. One size must fit all, or the rational basis of the entire project is challenged. This apparently neutral uniformity of correct procedure disguises the relationships of economic power that it both serves and mimics, and it rides roughshod over local values. Coupled with a political program of normalisation in Aboriginal affairs in Australia (Sullivan 2013), contemporary public management has facilitated the destruction of the Aboriginal community-controlled service sector since the abolition of the Aboriginal and Torres Strait Islander Commission (ATSIC) in 2005. Technical management institutes a form of cultural chauvinism through the Australian public sector's inability to appreciate Aboriginal forms of management; its inability to take into account the value provided by culturally informed local third-sector organisations; ${ }^{2}$ and its inability to hear local competence expressed in a dialect and idiom foreign to dominant public sector discourse.

In Australia, as in other modern societies, the Australian Government delivers many of its social, cultural and welfare services through the engagement of third-sector organisations. ${ }^{3}$ Many of these organisations are working in the field of 'internal development', particularly the Aboriginal third sector that struggles with the kind of poverty and lack of infrastructure normally associated with underdeveloped countries. Good practice in development programs requires attention to the process of program delivery as much as the outcome or targets (Mosse 1998: 4-5). Similarly, in complex, uncertain and rapidly changing environments, contemporary management scholarship emphasises the need for 'experimentalist' organisations at the level of project implementation (Sabel 2004). Both approaches, starting with different aims and from different

2 Third sector is a common term for non-state, non-commercial organisations that provide quasigovernmental services. They are formally independent of government, comprising NGOs, charities and other not-for-profit and civil society entities.

3 It also meets these objectives by subsidies to state governments. These more commonly deliver services directly through their own agencies, but also engage third-sector organisations. The states have not been prominent in Aboriginal development since 1967, but are now, in this phase of normalisation, being required by the Commonwealth to take responsibility for the Aboriginal citizens in much the same way as for the rest of their population. 
premises, therefore identify the need for significant local autonomy that recognises the diversity of program environments. Australia, in contrast, is still wedded to central planning, strict oversight of implementation, continual audit and interference and, throughout this, over-the-shoulder attention to political imperatives.

Data from interviews conducted with the CEOs and directors of 18 Aboriginal third-sector organisations in the Kimberley region of Western Australia in $2010^{4}$ show a sector that is demoralised by this new regime. Some of the challenges they face include competition, often with compatriot organisations, over available funds to deliver services; limitation to narrow service provision roles rather than providing multifaceted community resources; short time frame, remotely conceived, highly fragmented, report-driven government programs; and high churn in government agencies, related to NPM public sector job flexibility, producing debilitating corporate amnesia in the agencies that plan and distribute development programs.

At least part of the fragmentation of this sector is due to Australian monoculturalism, which is deaf to cultural nuances, so that third-sector organisations' statements about their learning, governance and relation to others in the sector quite literally cannot be heard. As one Aboriginal CEO of a long-established Aboriginal resource agency told Sullivan:

We broke into housing management four years ago and then that contract got taken off us. We used to manage [four communities] and they took that contract off us then said no, we're going to manage it ourselves and then just doubled the amount of funding available. Like up until the 31 st December 2009, they gave us $\$ 4,000$ per house to manage. Now when they're managing it, it's $\$ 8,000$ a house $\ldots$ Yeah they always had that luxury of going up to $\$ 8,000$, it's just that they made us work for $\$ 4,000$ a house, so that's $\$ 2,000$ operational funding and $\$ 2,000$ per house repairs and maintenance and then we had to collect at least $\$ 2,000$ per house to subsidise the R \& M budget. Repairs and Maintenance to the house. Repairs and Maintenance funding. And then like the following year you know they just doubled the funding, so it's again another case of you know making us sweat on a very restricted budget for a period of time and then all of a sudden, they do it or a non-indigenous contractor does it and the funding available blows out or doubles you know, like

4 Research undertaken in the Kimberley region by Sullivan in 2010 as a Senior Research Fellow at the Australian Institute of Aboriginal and Torres Strait Islander Studies. The data, which echoes HowardWagner (this volume, Chapter 12) for NSW, is largely unpublished, but see Sullivan (2011b). 
that's racism or something isn't it? I'm sure it is. It's just not right and I've got so many instances of it ... So you've got all this overload of State and Federal Governments just overloading them. [mimicking government liaison with the recipient communities] Oh yeah we're here to do this you know. [his organisation] did a shit job, so that's why we stopped their contract. And believe me they have been running us down and that's why they promoted the non-Indigenous contractors to step in, and they made them look great and everything got done in the community but they were doing it for treble the amount of money that we did it for and they made us look terrible by doing that ... Of course I would have done that for $\$ 600,000$ too instead of $\$ 180,000$. I mean with $\$ 180,000 \mathrm{I}$ had to employ a manager out there, operate a couple of vehicles, couple of staff houses, run the shed out there, the power house. We were used as scapegoats you know and one would have to wonder what the reasoning or motives were behind that. Is it part of a larger scheme to downgrade community control of resource agencies and the role they play or what? I mean it just makes me a bit suspicious about their motives (Author's transcript of interview 2010, identity withheld).

Instead of experience and capability, the inner-oriented public administrator sees only lack of capacity. Australia is a consciously homogenising nation with a relatively low tolerance of diversity. NPM managerialism therefore has a kind of 'naturalness' that suits Australian historical, administrative and cultural conditions. The intersection of NPM central control and Australian unease with local, regional and ethnic diversity currently impacts heavily on the Aboriginal component of the Australian third sector. The sector is subject to inappropriate regulation, takeover by state government agencies and open-market commercialisation of welfare/development service delivery functions (see Sullivan 2010, Sullivan 2011c: 8-9, Sullivan 2015). Aboriginal third-sector organisations are hampered in their ability to challenge this process by the inability of mainstream administrators to hear and credit the culturally inflected voices of Aboriginal management at the local level.

The Australian Government predominates in Australia because it has increasingly monopolised the capacity for revenue-raising throughout the country. The federal government provides few direct services. Its major service functions are those that are not easily outsourced-particularly defence and tertiary education that, in 2010, together accounted for 290,534 of the 367,845 people employed by the government. The remaining public servants either provide services within government itself or are desk-controllers of direct service providers in state government 
agencies and in the third sector (see Parliament of Australia 2010b: 7). While not being much of a service provider itself, the Australian Government controls services throughout Australia through commercial tendering, grants to state and local governments, and to third-sector organisations.

This fiscal bedrock of Australian society, largely unacknowledged by its citizens, is horizontal fiscal equalisation (see Yu et al. 2008: 50-1). It is the fiscal policy of the federal government that transfers central funds to the states to 'fill in the gaps' of fiscal capacity so that Australians experience broadly the same level of services and infrastructure across the country. It intersects with its demographic profile to underpin Australian monoculturalism. By far the largest proportion of Australian non-Indigenous people live in major cities or towns (about 88 per cent of the total population) (Australian Bureau of Statistics 2008: 9). These are usually situated on a river system close to the coast. A further 9.5 per cent live in outer regional areas (ibid.). Their expectation, largely fulfilled, is that their experience of one major city or regional centre will be very much the same as another as they travel about the country. This is quite a remarkable achievement in a country of such physical size. It does, however, encourage monoculturalism.

Monoculturalism is explicitly embraced by conservative liberalism, and it surfaces both in approaches to immigration and to Aboriginal affairs. It is well articulated by the most successful Australian prime minister of recent decades, John Howard, in a speech to The Margaret Thatcher Centre for Freedom in 2010. In this speech, he celebrated the common values of 'the Anglosphere', which he took to include Canada, the United States and New Zealand, all countries with significant indigenous populations:

I think one of the errors that some sections of the English-speaking world have made in the past few decades has been to confuse multiracialism and multiculturalism. I am a passionate believer in multiracialism. I believe that societies are enriched if they draw, as my country has done, from all parts of the world on a non-discriminatory basis, and contribute, as the United States has done, to the building of a great society. But when a nation draws people from other parts of the world, it draws them because of the magnetism of its own culture and its own way of life, and the ideal, in my opinion, is to draw people from the four corners of the earth but to unite them behind the common values of the country which has made them welcome (Howard 2011: 5). 
Howard speaks to the core values of 'old Australia', an Australia eager to rid itself of the international ignominy of race discrimination, but uncomfortable still with cultural diversity. This is both philosophical and emotional. On a philosophical level, it is indeed confronting to deal with competing systems of value, such as conceptions of right and wrong and the origins of social authority. However, the monoculturalism represented by politicians such as Howard is not simply a matter of intellectual struggle, but is also an appeal to cultural chauvinism. In the public service, this manifests as an inability to credit non-standard voices, and Aboriginal managers are deemed to 'lack capacity' simply because of the way they talk, behave and present themselves and the values of their communities.

\section{The public value of Aboriginal organisations}

The practices and ideologies described so far in this chapter support Strakosch's identification of lack of capacity and risk as the means by which the neoliberal state resiles from traditional liberal values that recognise citizen and minority rights. She identifies two distinct directions of neoliberal critique. One analyses neoliberalism as 'the decline of the state in favour of the market'; in other words, structural economic change (Strakosch 2015: 36). The other, Foucauldian, approach emphasises governmentality:

the mobile technologies of government that activate and work through the calculative freedom of individuals. Such technologies include contractualism, privatisation, marketisation and the fostering of 'active' self-regulating citizenship (Strakosch 2015: 37).

In either case, in my view, the technology of neoliberal control is the same. It is the apparently neutral and scientific application of public management principles. This is therefore an arena where resistance and reform can potentially be mounted. One way to do this is to advance alternative approaches to public management in liberal societies. This is what Mark Moore does with his theory of public value (Moore 1995, 2013).

The concept of public value was advanced by Moore in the early 1980s when neoliberal public management first threatened to dominate the administrative apparatus of the Anglophone states. It has been refined since, and offers an alternative approach, now that neoliberal public management faces widespread public disillusion. Moore said that neoliberal public management mimics the production of private value in 
the commercial, market-oriented sector because of its perceived efficiency. One way that modern bureaucracies got this wrong, he believes, is by concentrating on the internal organisation of bureaucracies, introducing rigorous control, performance management and line accountability; whereas commercial organisations are typically less self-centred and are outwardly directed towards their customers and clients. Nevertheless, this form of rigorous governance is visited upon Aboriginal organisations by bureaucrats in the firm belief that it is more efficient. Moore nevertheless proposed that public value is fundamentally different to private value, and that it is wrong for public administrators to ignore these differences. One principal difference is that the process of producing a public good is itself intrinsic to its value, while the process of producing a private commodity for the commercial market is immaterial to its perceived value among the private organisations' customers. This opens up a second difference that was not explored by Moore. Public administrators should take into account a range of values desired by a range of publics, adapting their processes of value production, offering the possibility of putting Aboriginal values and Aboriginal publics at the forefront of Aboriginal policy once more.

Moore realised that public values are produced in the instrumental processes of governmental activity, not simply as an outcome. Citizens derive value by being treated in ways that acknowledge their rights, their dignity and their own culturally mediated understanding of civility. Neoliberal public administration, in contrast, mimics an economic market in which the goods or services provided are apparently divorced from the process that produces them. All that matters is that the process should be efficient. As a result, citizens may have become well-serviced but alienated from the administrative structures of government that ought to reflect their underlying sovereignty.

Moore's (1995) conception is dynamic. It involves negotiation between citizens, administrators and politicians in an active environment of desire for public benefit and the limiting of public harm. Moore tells the public servants of advanced democracies that they need to define public value in particular circumstances, build the operational capacity within and outside of the public service to deliver it and to do this within an accepted 'authorizing environment' (Benington \& Moore 2011: 4). It is this idea of an 'authorizing environment' that delivers some tools to community-based service organisations to construct their counter arguments to bureaucrats whose only knowledge of public administration is passive absorption of 
NPM. Although a public servant's mandate comes from the legislation informed by the values of the ruling party, this is not a guarantee that they are providing public value (Benington \& Moore 2011: 6). Many community workers in Aboriginal development would argue that, in complex intercultural development programs, a simple mandate deriving from legislation is never sufficient. It is more common that:

public policymaker and manager may have to create a network of partners and stakeholders, and to negotiate a coalition of different interests and agencies (from across public, private, voluntary and informal community sectors) to support them in achieving their goals (Benington \& Moore 2011: 6).

Moore calls this the 'authorizing environment' within which public administrators can create value. Moore says the support of 'a coalition of stakeholders from the public, private and third sectors ... is required to sustain the necessary strategic action' (Benington \& Moore 2011: 4).

Moore's insistence that the role of the public manager is to encourage the creation of public value does not deny the importance of good management practice in organisations (Hood 1991, cited in Benington \& Moore 2011: 10). However, management must be turned towards those things that the public as a whole values, and the public is more than a mob of individuals corralled into a consumer group. Much could be said about the constitution of the various publics (see Warner 2002), but here we can note that there are local Aboriginal publics with distinct values that can clearly be better represented when public managers are responsive to an authorising environment that includes their representative organisations and their significant spokespeople knowledgeable in lore and culture. This is an authorising environment that includes politicians and their programs, but also informs them both in a two-way process that requires workable trade-offs (Alford \& O'Flynn 2009, cited in Benington \& Moore 2011: 5).

Underpinning public value, according to Moore's original vision of the concept, is acknowledgement that benefits generally arise when governments, public servants and the public have a shared purpose. In the case of Aboriginal organisations and government, that shared vision has largely been absent or, at best, certainly not at the forefront of policy thinking, if it can ever be said to have existed in any influential sense. The Indigenous Advancement Strategy (see Page this volume, Chapter 10) and the current government's responses to the Community Development 
Employment Projects program are two examples that vividly illustrate the lack of shared purpose, or shared conceptions of what constitutes public value to an Aboriginal public. Nevertheless, the concept of public value remains a form of contemporary nomenclature that offers an opportunity to make visible the full value of Aboriginal organisations to their publics in a manner intelligible to government, with potential to help restore a greater level of shared vision or, less ambitiously, to present a more realistic view of the valuable services these organisations provide. In short, it is an opportunity to develop a grounded counter-discourse that moves us away from punishment and disparagement.

Critics of increasing state control of every facet of daily life must become aware of, and be prepared to deploy, this significant counter-discourse in public sector management theory, fighting back with the argument that the task of public management is the creation of public value, and this is determined by local publics. This counter-discourse argues for the effectiveness of flexible pragmatic adaptive management at the local level (Sabel 2004), and for relational contracts that establish the terms of engagement rather than the precise product to be delivered (Mcneil 1978, Dwyer et al. 2009). These are alternative streams of public management theory that have at least as much coherence as neoliberal public management. They affect equally the way that civil society organisations themselves organise. No matter how much we attempt to resist the dehumanising effect of bureaucracy, we cannot escape the need to organise, and therefore to pursue appropriate forms of public management. Weber foresaw this double bind of bureaucracy (Jacoby 1973: 151-2). Modern bureaucracy is ruthlessly efficient, but efficiently organising against it effectively risks reproducing and perpetuating it. Resistance is important, but seeking out alternatives is also necessary. While a valid reaction to the totalising effect of bureaucracy is to subvert, undermine and resist, another is to reform, to humanise bureaucracy, so that it becomes adequate for the task of realising the values of citizens, not least Indigenous citizens holding values rooted in a society that long pre-dates their colonisation.

\section{References}

Alford J \& O'Flynn J (2009). Making sense of public value: Concepts, critiques and emergent meanings. International Journal of Public Administration. 32:171-91. 
Australian Bureau of Statistics (2008). Australian social trends, 2008, cat. no. 4102.0, Australian Bureau of Statistics, Canberra.

Benington J \& Moore M (eds) (2011). Public value: Theory and practice, Palgrave Macmillan, Basingstoke, doi.org/10.1007/978-0-230-36431-8.

Dwyer JM, Lavoie J, O’Donnell K, Marlina U \& Sullivan, P (2009). The overburden report: Contracting for Aboriginal health services, Cooperative Research Centre for Aboriginal Health, Darwin.

Eckersley R (2003). Politics and policy. In Dovers S \& Wild River S (eds), Managing Australia's environment, Federation Press, Sydney.

Hood, C (2006). Gaming in targetworld: The targets approach to managing British public services. Public Administration Review 66(4):515-21. doi.org/10.1111/ j.1540-6210.2006.00612.x.

Howard J (2011). The anglosphere and the advance of freedom, the Margaret Thatcher Freedom Lecture, 24 September 2010, the Heritage Foundation, Washington, www.heritage.org/report/the-anglosphere-and-the-advance-freedom.

Jacoby H (1973). The bureaucratization of the world, University of California Press, Berkeley.

Kaboolian L (1998). The new public management: Challenging the boundaries of the management vs administration debate, Public Administration Review 58(3):189-93.

Mcneil I (1978). Contract: Adjustment of long-term economic relations under classical, neo-classical and relational contract law. North-western University Law Review 72(6):854-905.

Moore MH (1995). Creating public value: Strategic management in government, Harvard University Press, Massachusetts.

Moore MH (2013). Recognizing public value, Harvard University Press, Massachusetts.

Mosse D (1998). Process-oriented approaches to development practice and social research. In Mosse D, Farrington J \& Rew A (eds), Development as process: Concepts and methods for working with complexity, Routledge, London.

Nelson H (2008). Public employment in Australia: In competition with the market. In Hans-Ulrich D and Guy Peters B (eds), The state at work, volume 1, Edward Elgar, Cheltenham, doi.org/10.4337/9781848444942.00009. 
Neu D (2003). Accounting for the banal: Financial techniques as softwares of colonialism. In Anshuman P (ed.), Postcolonial theory and organisational analysis: A critical engagement, Palgrave, NewYork.

O’Flynn J (2007). From new public management to public value: Paradigmatic change and managerial implications. The Australian Journal of Public Administration 66(3):357-8, doi.org/10.1111/j.1467-8500.2007.00545.x.

Parliament of Australia (2010a). Chronology of changes in the Australian public service 1975-2010, Background Note, Parliamentary Library, Department of Parliamentary Services, Canberra.

Parliament of Australia (2010b). How many are employed in the commonwealth public sector? Background Note, Parliamentary Library, Department of Parliamentary Services, Canberra.

Power M (1997). The audit society: Rituals of verification, Oxford University Press, Oxford.

Sabel CF (2004). Beyond principal-agent governance: Experimentalist organizations, learning and accountability. In Engelen E \& Sie Dhian Ho M (eds), De Staat van de Democratie. Democratie voorbij de Staat [The state of democracy. Democracy beyond the state]. WRR Verkenning 3 Amsterdam: Amsterdam University Press.

Stoker G (2006). Public value management: A new narrative for networked governance? American Review of Public Administration 1(3):41-57, doi.org/ $10.1177 / 0275074005282583$.

Strakosch E (2012). Colonial risk management. Borderlands 11(1), www.border lands.net.au./vol11no1_2012/strakosch_risk.htm

Strakosch E (2015). Neoliberal Indigenous policy: Settler colonialism and the 'post-welfare' state, Palgrave Macmillan, Hampshire, doi.org/10.1057/ 9781137405418.

Sullivan P (1991) [1989]. All free man now: Culture and post-colonialism in the Kimberley Division North-Western Australia. PhD thesis, The Australian National University, Canberra.

Sullivan P (1996). All free man now: Culture, community and politics in the Kimberley Region North Western Australia, Aboriginal Studies Press, Canberra.

Sullivan P (2006a). Softwares of colonialism: Contradictions of accountability in whole-of-government policy for indigenous affairs. Seminar presentation, 3 May, Centre for Aboriginal Economic Policy Research, The Australian National University, Canberra. 
Sullivan P (2006b). Softwares of modernity: Accountability and the culture of bureaucracy in Australian Aboriginal affairs administration. Paper delivered to the symposium Current Developments in Ethnographic Research in the Social and Management Sciences, Liverpool University Management School, 13-14 September.

Sullivan P (2008). Bureaucratic process as Morris dance: An ethnographic approach to the culture of bureaucracy in Australian Aboriginal affairs administration. Critical Perspectives on International Business 4(2/3):127-41, doi.org/10.1108/17422040810869981.

Sullivan P (2009). Reciprocal accountability: Assessing the accountability environment in Australian Aboriginal affairs policy. International Journal of Public Sector Management 22(1):57-71, doi.org/10.1108/ 09513550910922405.

Sullivan P (2010). The Aboriginal community sector and the effective delivery of services: Acknowledging the role of Indigenous sector organisations, Working Paper 73, Desert Knowledge Cooperative Research Centre, Alice Springs.

Sullivan P (2011a). Belonging together: Dealing with the politics of disenchantment in Australian Aboriginal policy, Aboriginal Studies Press, Canberra.

Sullivan P (2011b) Third sector Aboriginal organisations in Australia and the new wave of normalisation. Paper delivered to stream Shaping the Spaces Between State and Market: Critical Perspectives on the 'Third Sector', 7th International Critical Management Studies Conference, Naples, Italy, 11-13 July.

Sullivan P (2011c). The policy goal of normalisation, the national Indigenous reform agreement and Indigenous national partnership agreements, Working Paper 76, Desert Knowledge Cooperative Research Centre, Alice Springs. www.nintione.com.au/resource/NintiOneWorkingPaper_76_PolicyGoalof Normalisation.pdf.

Sullivan P (2013). Disenchantment, normalisation and public value: Taking the long view in Australian Indigenous affairs. The Asia Pacific Journal of Anthropology 14(4):353-69, doi.org/10.1080/14442213.2013.804871.

Sullivan P (2015). A reciprocal relationship: Accountability for public value in the Aboriginal community sector, Lowitja Institute, Melbourne.

Warner M (2002). Publics and counterpublics (abbreviated version). Quarterly Journal of Speech, 88(4):413-25.

Yu P, Duncan E \& Gray B (2008). Report of the Northern Territory Emergency Response Review Board, Commonwealth of Australia, Canberra. 
This text is taken from The Neoliberal State, Recognition and Indigenous Rights: New paternalism to new imaginings, edited by Deirdre Howard-Wagner, Maria Bargh and Isabel AltamiranoJiménez, published 2018 by ANU Press, The Australian National University, Canberra, Australia.

doi.org/10.22459/CAEPR40.07.2018.11 